\title{
Principio de favorabilidad de las normas sustantivas en materia tributaria. Choque de trenes entre la Corte Constitucional y el Consejo de Estado*
}

doi:10.11144/Javeriana.cc16-41.pfns

\section{Carlos Mario Restrepo-Pineda}

Docente, Escuela de Posgrados de la Universidad Autónoma Latinoamericana, UNAULA. Magíster en derecho procesal, Universidad de Medellín. Especialista en legislación tributaria, UNAULA. Especialista en derecho procesal contemporáneo, Universidad de Medellín. Abogado, Universidad de Antioquia. Contador público, UNAULA. Pertenece al Grupo de Investigación GIP de la UNAULA. Correo electrónico: cmrp@hotmail.com

\footnotetext{
* Este artículo de reflexión es producto de la investigación Alcance de la aplicación del principio de favorabilidad en el derecho tributario en Colombia, llevada a cabo por el Grupo de Investigación Pluriverso (GIP) de la Universidad Autónoma Latinoamericana (UNAULA), Medellín, Colombia, registrado en Colciencias
} 
Resumen En el derecho administrativo especial tributario, la norma sustantiva se refiere a los elementos estructurales del tributo: el sujeto pasivo, el sujeto activo, el hecho generador, la base gravable y la tarifa. El principio de favorabilidad de las normas sustantivas en materia tributaria, referente a impuestos de período, se entiende como la aplicación de las normas sustantivas que disminuyen o eliminan las cargas tributarias siendo favorable al contribuyente, en el mismo período fiscal en que entró en vigencia la norma. La forma como está redactado el inciso tercero del artículo 338 de la Constitución al interpretarlo en armonía con el inciso segundo del artículo 363 constitucional genera confusiones o disyuntivas en cuanto a la aplicación de este principio.

El presente artículo tiene como objetivo puntualizar la línea jurisprudencial de la Corte Constitucional y del Consejo de Estado con el fin de hacer un análisis comparativo acerca de la aplicación del principio de favorabilidad de las normas sustantivas en el derecho tributario.

La línea jurisprudencial de cada una de estas dos Corporaciones se ha construido siguiendo la metodología propuesta por Diego Eduardo López-Medina, que consiste en hacer una pregunta orientadora. En este caso: ¿aplica el principio de favorabilidad de las normas sustantivas en materia tributaria? Con dos polos de respuesta — sí y no-, para el efecto se tomó el lapso que va de 1993 a 2014, en el que se rastrearon las sentencias de ambas corporaciones, se identificó la sentencia más reciente denominada sentencia arquimédica. Luego, mediante las citas de la sentencia, se fueron detectando otras sentencias referentes al mismo tema, hasta llegar a la sentencia fundante de la línea; entre los dos extremos - la sentencia arquimédica y la sentencia fundante-, quedaron las demás sentencias organizadas cronológicamente. Después, luego se observó qué resultado se obtuvo, que puede ser una línea coherente o una línea caótica (López-Medina, 2000, pp. 142-147).

En el caso del Consejo de Estado se encontraron 18 sentencias, y en el de la Corte Constitucional, 15 sentencias. Este artículo presenta la línea jurisprudencial de la Corte Constitucional y del Consejo de Estado, junto con los hallazgos, conclusiones y recomendaciones alrededor del tema.

Palabras clave Norma sustantiva; favorabilidad; principio de favorabilidad; aplicación retrospectiva de la ley; aplicación retroactiva de la ley; derechos adquiridos; derechos consolidados; meras expectativas de derecho

\section{Código JEL K41, K34, H25}

\section{Favorability Principle of the Substantive Rule on Tax Matters. Train Wreck Between the Constitutional Court and the State Council}

Abstract In special tax administrative law, the substantive rule refers to the structural elements of tax: taxpayer, tax collector, taxable event, basis of assessment, and the rate. The favorability principle of the substantive rule on tax matters, regarding period taxes, is understood as the application of substantive rules that reduce or eliminate tax burdens, favoring the taxpayer in the same period the rule became effective. The way paragraph three of article 338 of the Constitution is redacted, when interpreted under the light of paragraph two of article 363 of the Constitution creates confusions or quandaries regarding the application of this principle. The purpose of this article is to clarify the case law line of the Constitutional Court and the State Council as to carry out a comparative analysis of the application of the favorability principle of substantive rule on tax law. The case law line of each one of these two Corporations was built using the methodology proposed by Diego Eduardo López-Medina, which is based on the formulation of a guiding question. In this case, that would be: Does the favorability principle of substantive rule apply on tax matters? With two sides for an answer - yes and no- and to this end we took the period between 1993 to 2014, we tracked the rulings of both corporation and identified the most recent ruling, called Archimedes' ruling. Then, by means of citations in the ruling, we detected other rulings refe- 
PRINCIPIO DE FAVORABILIDAD DE LAS NORMAS SUSTANTIVAS EN MATERIA TRIBUTARIA / C. RESTREPO / 431

rring to the same topic until we tracked down the founding ruling of the line: between the two extremes - the Archimedes' ruling and the founding ruling- all other rulings were chronologically organized. After that, we observed the result obtained, which may be a coherent or a chaotic line (López-Medina, 2000, pp. 142-147). In the case of the State Council we found 18 rulings and for the case of the Constitutional Court, 15 rulings. This article presents the case law line of the Constitutional Court and the State Council alongside the findings, conclusions, and recommendations on the topic.

Keywords substantive law; favorability; favorability principle; retrospective application of law; retroactive application of law; acquired rights; vested rights; mere expectations of law

\section{Princípio de favorabilidade das normas substantivas em matéria tributária. Choque de trens entre a Corte Constitucional e o Conselho de Estado}

Resumo No direito administrativo especial tributário, a norma substantiva refere-se aos elementos estruturais do tributo: o sujeito passivo, o sujeito ativo, o fato gerador, a base gravável e a tarifa. O princípio de favorabilidade das normas substantivas em matéria tributária, referente a impostos de período, entende-se como o aplicativo das normas substantivas que diminuem ou eliminam o ônus tributários, sendo favorável ao contribuinte, no mesmo período fiscal em que entrou em vigência a norma. A forma como está redigido o inciso terceiro do artigo 338 da Constituição ao interpretar em harmonia com o inciso segundo do artigo 363 constitucional gera confusões ou disjuntivas quanto ao aplicativo deste princípio. O presente artigo tem como objetivo pontuar a linha jurisprudencial da Corte Constitucional e do Conselho de Estado com o fim de fazer uma análise comparativa a respeito do aplicativo do princípio de favorabilidade das normas substantivas no direito tributário. A linha jurisprudencial de cada uma destas duas
Corporações construiu-se seguindo a metodologia proposta por Diego Eduardo López-Medina, que consiste em fazer uma pergunta orientadora. Neste caso: aplica-se o princípio de favorabilidade das normas substantivas em matéria tributária? Com dois polos de resposta — sim e não-, para o efeito se tomou o lapso que vai de 1993 a 2014, no qual se rastrearam as sentenças de ambas corporações, se identificou a sentença mais recente denominada sentença arquimédica. Depois, mediante citações da sentença, foram se detectando outras sentenças referentes ao mesmo tema, até chegar à sentença fundante da linha; entre os dois extremos - a sentença arquimédica e a sentença fundanteficaram as outras sentenças organizadas cronologicamente. Depois, observou-se qual resultado se obteve, o que pode ser uma linha coerente ou uma linha caótica (López-Medina, 2000, pg. 142-147). No caso do Conselho de Estado encontraram-se 18 sentenças, e no da Corte Constitucional, 15 sentenças. Este artigo apresenta a linha jurisprudencial da Corte Constitucional e do Conselho de Estado, junto com o que se encontrou, conclusões e recomendações ao redor do tema.

Palavras-chave Norma substantiva; favorabilidade; princípio de favorabilidade; aplicação retrospectiva da lei; aplicação retroativa da lei; direitos adquiridos; direitos consolidados; meras expectativas de direito

\section{Introducción}

El artículo 363 de la Constitución dice: "El sistema tributario se funda en los principios de equidad, eficiencia y progresividad. Las leyes tributarias no se aplicarán retroactivamente", de lo cual es dable interpretar que la norma tributaria no se aplica a hechos ocurridos antes de su entrada en vigencia, es decir, hacia el pasado.

Así mismo, el artículo 338 en su inciso 3 dispone el momento a partir del cual se apli- 
can las normas tributarias para los tributos de período. Dice textualmente esta norma: "Las leyes, ordenanzas o acuerdos que regulen contribuciones en las que la base sea el resultado de hechos ocurridos durante un período determinado no pueden aplicarse sino a partir del período que comience después de iniciar la vigencia de la respectiva ley, ordenanza o acuerdo", por lo que la interpretación literal de este inciso indica que si la norma afecta la estructura de un impuesto de período, se debe aplicar en el período que comience después de su entrada en vigencia; por lo tanto, no podría ser aplicable en el mismo período de su entrada en vigencia, pues estaríamos ante un supuesto de retroactividad, proscrito por el artículo 363 de la Constitución.

Una pregunta que surge es: ¿qué ha de entenderse por el período siguiente? cuando el texto del artículo 338 dice “...no pueden aplicarse sino a partir del período que comience después de iniciar la vigencia de la respectiva ley, ordenanza o acuerdo...", de ahí que por la forma en que está redactada la norma, se generan confusiones o disyuntivas relacionadas con la aplicación del principio de favorabilidad de las normas sustantivas en materia tributaria, relacionada con el alcance de la palabra "período". Aquí surgen las siguientes preguntas: ¿en cuál período fiscal se aplica la norma tributaria que entra en vigencia en una fecha determinada? ¿Se aplica después de iniciar su vigencia, en el mismo período fiscal en que entró en vigencia, o se aplica después de iniciar su vigencia, en el período fiscal siguiente al de su entrada en vigencia? ¿Para su aplicación interesa o no que la norma sea favorable al contri- buyente en el sentido de disminuir o eliminar cargas tributarias?

Como se observará en el presente escrito, tanto la Corte Constitucional como el Consejo de Estado interpretan de forma diferente el alcance de la aplicación de las normas tributarias en el mismo período fiscal de su entrada en vigencia, lo que repercute en la aplicación o no del principio de favorabilidad de las normas sustantivas en materia tributaria. Para entender la posición asumida por cada una de estas Corporaciones, se debe tener especial cuidado en el alcance que se le da a la palabra "período".

El profesor Jesús Orlando Corredor-Alejo ha encontrado que la Corte Constitucional, al interpretar el sentido de la palabra "período" contenida en el artículo 338 de la Constitución, no le da el mismo alcance que tiene esta palabra cuando es interpretada en la expresión "período gravable", donde la palabra gravable como adjetivo está calificando al sustantivo, de ahí que esta Corporación interpreta la palabra "período" desprovista de adjetivo que la califique, por lo tanto la palabra "período" se refiere al espacio de tiempo (Corredor-Alejo, 2011, p. 53); y este es uno de los argumentos por los cuales la Corte Constitucional llega a la conclusión que no hay transgresión de los artículos 338 inciso 3 y 363 inciso 2 de la Constitución, cuando la ley ordena que una norma entre a aplicarse en el mismo período gravable en que ha entrado en vigencia cuando se trata de normas favorables al contribuyente; en contraste, el Consejo de Estado llega a la conclusión de que se viola el artículo 338 inciso 3 y el artículo 363 inciso 2 de la Constitución, cuando la ley ordena que una norma entre a aplicarse en el mismo perío- 
do gravable en que ha entrado en vigencia aun cuando se trata de normas favorables al contribuyente.

\section{Línea jurisprudencial de la Corte Constitucional acerca de la aplicación del principio de favorabilidad de las normas sustantivas en el derecho tributario}

A continuación, se presentan las sentencias que constituyen la línea jurisprudencial de la Corte Constitucional acerca de la aplicación del principio de favorabilidad de las normas sustantivas en el derecho tributario, en las cuales establece que sí es dable su aplicación. Como se observará, esta corporación crea jurisprudencialmente este principio. Además, su línea jurisprudencial al respecto ha sido concisa, para lo cual se ha apoyado en argumentos referentes a los conceptos jurídicos de las meras expectativas de derecho y los derechos adquiridos en el derecho civil; este último concepto equivale en el derecho administrativo a los derechos consolidados, los cuales son aquellos que hacen parte del haber patrimonial de la persona, además del alcance del significado que la palabra "período" contenida en el artículo 338 del inciso 3 va a tener para esta corporación.

Sentencia C-149-93. Se expone esta sentencia en primer lugar, porque fue la primera sentencia en la que se abordaron los artículos 363 inciso 2, y 338 inciso 3, de la Constitución de 1991, para establecer si una norma que había entrado en vigencia en un período gravable, se podía aplicar en el mismo período gravable de su entrada en vigencia. Con respecto a este pronunciamiento, se comenta que la norma demandada en este caso aumentaba las cargas tributarias del contribuyente, por lo tanto era una norma sustantiva desfavorable; de ahí, la Corte Constitucional infiere que su aplicación se difiere hasta el 1 de enero de 1993. Pues las normas desfavorables se aplican en el período fiscal siguiente al de su entrada en vigencia.

En esta sentencia, la Corte Constitucional argumenta que la retroactividad del impuesto riñe abiertamente con los mandatos contenidos en los artículos 363 inciso 2 y 338 inciso 3 de la Constitución de 1991, pues al aplicar estas normas a la materia que se examina resulta ser palmaria su oposición, ya que la base del impuesto creado es el resultado de hechos ocurridos durante el período tributario de 1991 que concluyó el 31 de diciembre de ese año, mucho antes de la fecha en la cual comenzó la vigencia de la Ley 6 de 1992 [fecha de su publicación: 30 de junio de 1992]. Fue, entonces, violado de modo flagrante el inciso 3 del artículo 338 de la Constitución. A la luz de esta disposición, la contribución ordenada no podía ser aplicada sino a partir del período que comenzó a contarse el 1 de enero de 1993. Por lo tanto, la norma tributaria en este caso fue claramente retroactiva, en cuanto operó respecto de situaciones ya consolidadas, desconociendo lo estatuido en el artículo 363, inciso 2, de la Carta Política (Sentencia C-149-93).

Sentencia C-527-96. Con esta sentencia se inicia la línea jurisprudencial acerca de la aplicación del principio de favorabilidad en el derecho tributario. Se concluye en esta sentencia que si una norma beneficia al contribuyente, se 
puede aplicar en el mismo período en que inicia su vigencia.

Dice la Corte Constitucional que la palabra "período" no denota el significado que tiene la palabra cuando se interpreta junto a período gravable, pues la palabra gravable es el adjetivo que está calificando al sustantivo período, de ahí que la Corte Constitucional interprete la palabra "período" como el espacio de tiempo y que el máximo tribunal constitucional diferencie dos períodos dentro del mismo año en que la norma entró en vigencia. La norma tributaria más favorable al contribuyente sí aplica en el mismo período en que entró en vigencia la norma, solo que a partir del día de su promulgación, que en este caso coincide con el día de su entrada en vigencia (Sentencia C-527-96).

Carolina Ariza-Zapata sostiene que esta sentencia se puede clasificar como la sentencia fundadora de la línea de interpretación que da como resultado la aplicación al principio de favorabilidad en el derecho administrativo especial tributario (Ariza-Zapata, 2012, pp. 307308). Esta sentencia será citada en sentencias posteriores.

Sentencia C-185-97. En esta sentencia, la Corte Constitucional confirma el principio establecido en la Sentencia C-527-96. Si una norma beneficia al contribuyente, tiene efecto inmediato y comienza a aplicarse a partir de su promulgación. Se interpreta que el efecto de las normas favorables - si son derogatorias - se extiende a todo el período gravable en que la ley entró en vigencia, y no solamente a partir del día siguiente al de su vigencia (Sentencia C-185-97).

Sentencia C-006-98. En esta sentencia, la Corte Constitucional confirma el principio establecido en la Sentencia C-527-96. Si una norma beneficia al contribuyente, se puede aplicar en el mismo período en que inicia su vigencia. Así, esta corporación cambia el criterio de retrospectividad acogido en la Sentencia C-185-97, con la cual interpreta que la norma favorable se podía aplicar a todo el período en el que entró en vigencia, y acoge de nuevo el criterio de reparto de la anualidad, de la Sentencia C-527-96, que consiste en crear dos subperíodos dentro del mismo período gravable, y aplicar la ley favorable en el mismo período en que entró en vigencia, pero solamente en relación con la fracción que se ocurra con posterioridad a la vigencia de la ley (Sentencia C-006-98).

Sentencia C-063-98. En esta sentencia, la Corte Constitucional adiciona la Sentencia C-185-97. Dice esta corporación que las derogaciones tributarias, cuando benefician al contribuyente, tienen efecto general inmediato, por lo tanto, comienzan a aplicarse a partir de su promulgación, pero a partir del día siguiente al de su vigencia, a menos que el legislador, de manera expresa e indubitable, advierta lo contrario (Sentencia C-063-98).

Sentencia C-926-00. Dice la Corte Constitucional en esta sentencia que una norma no puede ser retroactiva a no ser que se trate de garantizar el principio de favorabilidad (Sentencia C-926-00).

Sentencia C-619-01. En esta sentencia, la Corte Constitucional dice que si bien es válida la irretroactividad de la ley para evitar la vulneración de situaciones jurídicas consolidadas, ella se predica de los derechos adquiridos y no de meras expectativas de derechos (Sentencia C-619-01). 
Sentencia C-806-01. En esta sentencia, la Corte Constitucional interpreta que el inciso tercero del artículo 338 establece una prohibición, la de aplicar las normas tributarias en el mismo período gravable en que han entrado en vigencia cuando se trata de impuestos de período; la Corte dice que esta prohibición aplica para las normas desfavorables, entendidas estas, como aquellas que aumentan las cargas al contribuyente, para lo cual hace una cita de pie de página para indicar textualmente, que hace referencia a la ratio decidendi de la sanfrancia C-527-96, en la cual se indica que las normas favorables al contribuyente, que evitan que se aumenten sus cargas tributarias, por razones de justicia y equidad pueden aplicarse en el mismo período de su entrada en vigencia sin quebrantar la Constitución, ya que la prohibición contenida en el artículo 338 de la Constitución está encaminada a impedir que se aumenten las cargas al contribuyente. La Corte Constitucional fundamenta su decisión en la definición de la palabra "período" que hace en la Sentencia C-597-96 (Sentencia C-806-01).

Sentencia C-1251-01. La Corte Constitucional dice que en lo referente al inciso primero de la norma que se revisa, no advierte que se presente la alegada violación al principio constitucional de irretroactividad de la ley tributaria, puesto que el señalamiento del año fiscal 2000 como el momento a partir del cual la base gravable de impuesto predial será el valor que establece el contribuyente como autoavalúo - el cual debe corresponder como mínimo al avalúo catastral vigente al momento de su causación-, lejos de perjudicar a los sujetos pasivos de esta exacción los favorece. Dice esta corporación que aun admitiendo que el impuesto de renta es un impuesto de período y que como tal le sería aplicable el mandato del artículo 338 Superior, en virtud del cual las leyes, ordenanzas o acuerdos que regulen sus aspectos estructurales solo pueden aplicarse a partir del período que comience después de iniciar su vigencia, no existe ningún problema en que la medida contenida en el artículo 1 de la Ley 601 de 2000 sea aplicada en el período fiscal en el cual comenzó a regir este ordenamiento legal, toda vez que al haber eliminado la actualización automática del avalúo catastral con referencia al Índice de Precios al Consumidor [IPC], el impuesto a pagar a partir del año gravable de 2000 resulta ser más equitativo, dada la actual situación del mercado inmobiliario. Para esto cita argumentos de la Sentencia C-527-96 (Sentencia C-1251-01).

Sentencia C-809-07. En esta sentencia, la Corte Constitucional dice que las leyes tributarias no son retroactivas en el entendido de que los efectos producidos por la ley en el pasado debe respetarlos la ley nueva, por lo que las situaciones jurídicas consolidadas no pueden ser desconocidas por la ley derogatoria. Las situaciones jurídicas consolidadas son equivalentes a los derechos adquiridos y se diferencian de las meras expectativas (Sentencia C-809-07).

Sentencia C-952-07. En esta sentencia, la Corte Constitucional dice que el principio de irretroactividad de la ley prohíbe que en materia de tributos una ley tenga efectos con anterioridad a su vigencia, salvo que se trate de una disposición más favorable para el contribuyente. No afectar situaciones jurídicas consolidadas 
equivalentes a derechos adquiridos (Sentencia C-952-07).

Sentencia C-430-09. En esta sentencia, la Corte Constitucional confirma el principio establecido en la Sentencia C-527-96. Si una norma beneficia al contribuyente, se puede aplicar en el mismo período en que inicia su vigencia, respecto de los denominados tributos de período, siempre que los hechos económicos gravados no se hayan consolidado. Las normas favorables no solo se aplican desde el inicio de su vigencia, sino que aplican para todo el período en el cual inició su vigencia (Sentencia C-430-09).

Sentencia C-686-11. En esta sentencia, la Corte Constitucional ratifica su posición en cuanto a que las normas derogatorias en materia tributaria, si son favorables al contribuyente, aplican en el mismo período en que entraron en vigencia y se aplican a todo el período (Sentencia C-686-11).

Sentencia C-878-11. En esta sentencia, la Corte Constitucional dice que si una norma beneficia al contribuyente, se puede aplicar en el mismo período en que inicia su vigencia, siempre que los hechos económicos gravados no se hayan consolidado, caso en el cual se está ante el fenómeno de retrospectividad y no de la irretroactividad de la ley (Sentencia C-878-11).

Sentencia C-785 de 2012. En esta sentencia, la Corte Constitucional dice que si una norma beneficia al contribuyente se puede aplicar en el mismo período en que inicia su vigencia siempre que se respeten las situaciones jurídicas consolidadas (Sentencia C-785-12).

En la siguiente tabla se presenta la línea jurisprudencial de la Corte Constitucional.

¿Es dable la aplicación del principio de favorabilidad de las normas sustantivas en el
derecho tributario?

Tabla 1. Línea jurisprudencial de la Corte Constitucional Fuente: elaboración propia 
Como se puede apreciar en la anterior tabla, la Corte Constitucional interpreta que la aplicación de las normas favorables al contribuyente no debe aplazarse hasta el año siguiente al de su expedición, sino que pueden ser aplicadas para el período en que entró en vigencia. Considera esta corporación que cuando la norma dice textualmente que “...no pueden aplicarse sino a partir del período que comience después de iniciar la vigencia de la respectiva ley, ordenanza o acuerdo", la palabra "período" se refiere al instante que se sigue a la entrada en vigencia de la norma, y no al período en el que se forma la base gravable de los tributos de período.

La Corte Constitucional argumenta que el intervalo de tiempo que hay entre la fecha de la entrada en vigencia de la norma y el 31 de diciembre del período gravable en que entró en vigencia, se corresponde con el período siguiente al que hace alusión el texto del artículo 338 de la Constitución, con lo cual se crean dos subperíodos dentro del período gravable, uno que va desde el 1 de enero del período gravable hasta el día de la fecha de entrada en vigencia de la norma, y el otro que va desde el día siguiente a la fecha de entrada en vigencia de la norma y el 31 de diciembre del período gravable.

En definitiva, para la Corte Constitucional no hay violación del artículo 338 de la Constitución al aplicar la norma sustantiva favorable en el mismo período gravable en el que entró en vigencia, pues se está aplicando en el período siguiente al de su entrada en vigencia, y no es una aplicación retroactiva de la norma que viole el artículo 363 de la Constitución, por- que la norma se está aplicando a meras expectativas de derecho, y la razón es que el período gravable está en ejecución, y por lo tanto no se está aplicando la norma a derechos consolidados, que en términos tributarios equivalen a situaciones jurídicas consolidadas, ya que en este caso la situación jurídica se consolida al finalizar el último instante del período gravable, momento en el cual los derechos consolidados entran al patrimonio del Estado y salen del patrimonio del contribuyente, por lo tanto, la aplicación de la norma en el mismo período de su entrada en vigencia es una aplicación retrospectiva y no retroactiva de la norma.

En el gráfico 1, se muestra la situación planteada.

\section{Línea jurisprudencial del Consejo de Estado acerca de la aplicación del principio de favorabilidad de las normas sustantivas en el derecho tributario}

A continuación, se presenta la línea jurisprudencial del Consejo de Estado acerca de la aplicación del principio de favorabilidad de las normas sustantivas en el derecho tributario. Como se podrá observar, el Consejo de Estado ha negado la mayoría de las veces la aplicación de este principio, pues de dieciocho sentencias encontradas en el período de 1993 a 2014, en dieciséis sentencias se pronunció negando la aplicación del principio y solo en dos sentencias aceptó la aplicación del principio.

Sentencia de 15 de octubre de 1993, Expediente 4710. En esta sentencia, el Consejo 


\section{8 / VOL. 16 / NO. 41 / MAYO-ACOSTO 2015}



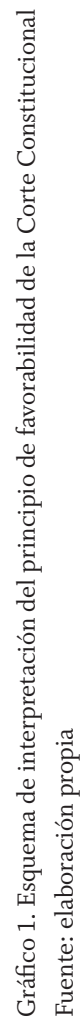


de Estado precisa su criterio en relación con la interpretación del artículo 338 de la Constitución. Dice la corporación que este artículo, en concordancia con el artículo 363 de la misma Constitución, consagra de manera enfática la irretroactividad de la ley, y específicamente para los tributos de período, dispuso que las normas que los regulen no puedan aplicarse sino a partir del período que comience después de iniciar la vigencia de la respectiva ley, ordenanza o acuerdo, es decir, toda norma que regule, y por lo tanto afecte alguno de los elementos estructurales de un tributo, que desde el punto de vista de la doctrina del Derecho Tributario son: los sujetos activos y pasivos, los hechos gravables, las bases gravables y las tarifas respectivas, tal como lo recoge el Estatuto Tributario, Decreto 624 de 1989, al referirse al origen de la obligación tributaria sustancial en el artículo 1 de su título preliminar. De acuerdo con lo anterior, toda norma que afecte los elementos estructurales debe entenderse como reguladora de un tributo y por ello, si se trata de un tributo de período, solo podrá aplicarse para el que comience después de iniciar su vigencia, independientemente del estatuto en que se encuentre contenida (Sentencia de 15 de octubre de 1993, Expediente 4710).

\section{Sentencia de 7 de febrero de 1997, Ex-} pediente 8036. En esta sentencia, el Consejo de Estado dice que con la disposición contenida en el último inciso del artículo 338 de la Constitución el constituyente quiso prohibir la aplicación retroactiva de la norma tributaria que bajo la figura de la "retrospectividad" había logrado hacer producir a la ley efectos sobre hechos económicos anteriores a su existencia con el argumento de la consolidación al final de un determinado período gravable. De ahí que la disposición constitucional haya ordenado la aplicación de la norma tributaria a partir del período fiscal que comience después de iniciar su vigencia, período fiscal que puede ser anual, bimestral, mensual o quincenal, según el tipo de tributo de que se trate (Sentencia de 7 de febrero de 1997, Expediente 8036).

Sentencia de 17 de abril de 1998, Radicado 8331. En esta sentencia, el Consejo de Estado se pronuncia acerca de la nulidad del Concepto 086277 de 1996 de la DIAN. La Ley 223 de 1995 derogó la deducción de la contribución especial del 25\% que debían pagar los contribuyentes, a partir de la vigencia de la misma, y se discute si esta contribución especial que debían pagar los contribuyentes por el año 1995 era o no deducible en 1996. Valiéndose de argumentos de la Corte Constitucional en las sentencias C-185-97 y C-063-98, el Consejo de Estado decide anular el Concepto 086277 de 1996 de la DIAN que había señalado que esa contribución no era deducible por el año 1996 (Sentencia de 17 de abril de 1998, Radicado 8331).

Como se puede observar en esta sentencia, el Consejo de Estado acepta la aplicación del principio de favorabilidad de las normas sustantivas en materia tributaria.

Sentencia de 5 de marzo de 1999, Radicado 9196. En esta sentencia, el Consejo de Estado dice que, de conformidad con el último inciso del artículo 338 de la Constitución, para las normas tributarias que regulen tributos de período, la disposición constitucional ha ordenado su aplicación a partir del período fiscal 
que comience después de iniciar su vigencia, período fiscal que puede ser anual, bimestral, mensual o quincenal, según el tipo de tributo de que se trate. Esta corporación dice que con esta disposición el Constituyente quiso prohibir la aplicación retroactiva de la norma tributaria que bajo la figura de la "retrospectividad" había logrado hacer producir a la ley efectos sobre hechos económicos anteriores a su existencia con el argumento de la consolidación al final de un determinado período gravable.

Sentencia de 19 de julio de 2000, Radicado 9907. En esta sentencia, el Consejo de Estado dice que al tenor de las normas constitucionales, las leyes, las ordenanzas o los acuerdos que regulen tributos cuya base sea el resultado de hechos ocurridos durante un período determinado, no pueden aplicarse sino a partir del período que comience después de iniciar la vigencia de la respectiva ley, ordenanza o acuerdo. Esta corporación dice que debe notarse cómo estas normas no señalan ninguna diferenciación en cuanto a si son "favorables o no al contribuyente" sino que de manera categórica proscriben la "retroactividad de la ley" (Sentencia de 19 de julio de 2000, Radicado 9907).

Sentencia de 7 de diciembre de 2000, Radicado 10445. En esta sentencia, el Consejo de Estado dice que en diversas oportunidades, ha reiterado que no es posible la aplicación inmediata de las normas reguladoras de tributos de período, ni la aplicación retroactiva de las leyes tributarias, pues ello implicaría la violación de las disposiciones constitucionales contenidas en los artículos 338 inciso 3 y 363 inciso 2, respectivamente (Sentencia de 7 de diciembre de 2000, Radicado 10445).
Sentencia de 3 de agosto de 2006, expediente 14897. En esta sentencia, el Consejo de Estado dice que las disposiciones contenidas en los artículos 338 y 363 de la Constitución, consagran el principio de irretroactividad de la ley tributaria, por cuanto en ellas se establece la prohibición de hacer efectiva de manera inmediata la norma reguladora de tributos de período, y de aplicar retroactivamente los preceptos fiscales, limitaciones que constituyen garantías para el contribuyente (Sentencia de 3 de agosto de 2006, expediente 14897).

Sentencia de 26 de octubre de 2006, Radicado 15177. En esta sentencia, el Consejo de Estado dice que se entiende que la disposición prevista en el artículo 7 de la Ley 863 de 29 de diciembre de 2003, está regulando un tributo, "en el que la base es el resultado de hechos ocurridos durante un período determinado", pues es evidente que la sobretasa constituye un gravamen adicional al Impuesto de Renta y constituye junto con este un solo tributo, cuyo período anual está previsto en el artículo 1 del Decreto 187 de 1975 desde el 1 de enero hasta el 31 de diciembre del respectivo año gravable.

Así las cosas, en aplicación del mandato constitucional contenido en el inciso 3 del artículo 338 de la Carta Política, debe entenderse que independientemente de que la Ley 863 haya entrado en vigencia el 29 de diciembre de 2003, todas las disposiciones que afecten alguno de los elementos que estructuran el tributo, entre ellas el artículo 7 que modifica la tarifa de la sobretasa de renta, solo pueden aplicarse "a partir del período que comience después de iniciar la vigencia de la respectiva ley...", es decir, 
a partir del año gravable 2004 (Sentencia de 26 de octubre de 2006, Radicado 15177).

En este caso, estamos ante normas desfavorables al contribuyente y como tales, deben aplicarse en el período fiscal siguiente.

Sentencia de 13 de septiembre de 2007, expediente 15503. En esta sentencia, el Consejo de Estado dice que en aplicación de los principios de equidad y justicia, procede el respeto de las situaciones jurídicas consolidadas bajo la vigencia de una ley anterior, es decir, que la ley nueva no puede desconocer los efectos que produjo la norma derogada o modificada durante su vigencia (Sentencia de 13 de septiembre de 2007, expediente 15503).

Sentencia de 21 de noviembre de 2007 , expediente 15584. El Consejo de Estado dice que debe advertirse que de conformidad con los artículos 338 y 363 de la Constitución Política, las normas tributarias no se aplican con retroactividad, y tratándose de impuestos cuya base sea el resultado de hechos ocurridos durante un período determinado, solo se aplican a partir del período que comience después de la vigencia de la ley.

El impuesto sobre la renta es un tributo de período que comienza el 1 de enero y termina el 31 de diciembre. Es decir, aquellas disposiciones que regulen el impuesto de renta no pueden aplicarse sino a partir del período gravable que comience después de iniciar la vigencia de la respectiva ley. Como ha señalado la Sala en ocasiones anteriores, no es posible la aplicación inmediata, ni la aplicación retroactiva de normas que afecten alguno de los elementos que estructuran el impuesto de período, pues ello implicaría la vulneración de las normas consti- tucionales ya mencionadas, disposiciones que precisamente procuran que los hechos ya formalizados jurídicamente y los que se encuentran en curso al momento de expedición de una ley, no se vean afectados por los cambios, en aras de la seguridad jurídica y de que haya certeza de las regulaciones de la obligación tributaria, previamente a la causación del impuesto (principio de legalidad). Para el caso de los tributos de período, las normas deben regir con anterioridad a su iniciación.

Los artículos 338 y 363 de la Carta Política proscriben de manera categórica la retroactividad de la ley, sin diferenciar si son o no favorables al contribuyente. La ley aplicable es la vigente al inicio del período. No tiene sustento alguno en el derecho tributario que se aplique el principio de favorabilidad propio de la legislación penal, pues los impuestos no constituyen un castigo, ni un agravio al contribuyente, sino que surgen de un deber de solidaridad de los ciudadanos, para coadyuvar con las cargas públicas. No puede considerarse desfavorable una norma fiscal que por principio pretende el bien común (Sentencia de 21 de noviembre de 2007, expediente 15584).

Sentencia de 31 de julio de 2009, expediente 16016. En esta sentencia, el Consejo de Estado dice que según el citado precepto constitucional, las disposiciones que regulan contribuciones de período no pueden aplicarse sino a partir del período posterior al de su entrada en vigencia y entre las normas que regulan tales tributos, están las que crean, modifican o extinguen cualquiera de los elementos esenciales de los mismos, como la pérdida de un beneficio tributario. 
Sobre el particular, la Sala ha precisado que no es posible la aplicación inmediata ni retroactiva de normas que afecten alguno de los elementos que estructuran un impuesto de período, pues ello implicaría la vulneración de los artículos 338 y 363 de la Constitución Política, "disposiciones que procuran que los hechos ya formalizados jurídicamente y los que se encuentran en curso al momento de expedición de una ley, no se vean afectados por los cambios, en aras de la seguridad jurídica y de que haya certeza de las regulaciones de la obligación tributaria, previamente a la causación del impuesto (principio de legalidad)" (Sentencia de 31 de julio de 2009, expediente 16016).

Sentencia de 26 de octubre de 2009, expediente 16665. En esta sentencia, el Consejo de Estado dice que según el artículo 338 inciso 3 de la Constitución, las disposiciones que regulan contribuciones de período no pueden aplicarse sino a partir del período posterior al de su entrada en vigencia $y$, en las normas que regulan tales tributos, se encuentran las que crean, modifican o extinguen cualquiera de los elementos esenciales de los mismos, como la pérdida de un beneficio tributario.

$\mathrm{Al}$ respecto, esta Sala ha sostenido que no es posible la aplicación inmediata ni retroactiva de normas que incidan directamente en alguno de los elementos estructurales de los impuestos de período, pues ello implicaría la vulneración de los artículos 338 y 363 de la Constitución Política, “disposiciones que procuran que los hechos ya formalizados jurídicamente y los que se encuentran en curso al momento de expedición de una ley, no se vean afectados por los cambios, en aras de la seguri- dad jurídica y de que haya certeza de las regulaciones de la obligación tributaria, previamente a la causación del impuesto (principio de legalidad)" (Sentencia de 26 de octubre de 2009, expediente 16665).

Sentencia de 26 de noviembre de 2009 , expediente 16928. En esta sentencia, el Consejo de Estado dice que los artículos 338 y 363 de la Constitución proscriben de manera categórica la retroactividad de la ley, sin diferenciar si son o no favorables al contribuyente. La ley aplicable es la vigente al inicio del período, al respecto esta corporación ha señalado que las normas tributarias no se aplican con retroactividad y, al tratarse de tributos cuya base sea el resultado de hechos ocurridos durante un período determinado, solo se aplican a partir del período que comience después de la vigencia de la ley. Agrega que el impuesto de renta es un tributo de período, pues se causa teniendo en cuenta el resultado económico del contribuyente en el año calendario que comienza el 1 de enero y termina el 31 de diciembre. Por lo tanto, aquellas disposiciones que regulen el impuesto de renta no pueden aplicarse sino a partir del período gravable que comience después de iniciar la vigencia de la respectiva ley. Indica el Consejo de Estado que, como ha señalado la Sala en ocasiones anteriores, no es posible la aplicación inmediata ni la aplicación retroactiva de normas que afecten alguno de los elementos que estructuran el impuesto de período, pues ello implicaría la vulneración de las normas constitucionales ya mencionadas, disposiciones que precisamente procuran que los hechos ya formalizados jurídicamente y los que se encuentran en curso al momento de expe- 
dición de una ley, no se vean afectados por los cambios, en aras de la seguridad jurídica y de que haya certeza de las regulaciones de la obligación tributaria, previamente a la causación del impuesto (principio de legalidad). Para el caso de los tributos de período, las normas deben regir con anterioridad a su iniciación.

Por lo tanto, concluye el Consejo de Estado que los artículos 338 y 363 de la Carta establecen la prohibición de hacer efectiva de manera inmediata la norma reguladora de tributos de período y de aplicar retroactivamente los preceptos fiscales, limitaciones que constituyen garantías para el contribuyente. Esta corporación precisa que, aunque la norma en cuestión no modifica un elemento del tributo, el principio de irretroactividad se aplica independientemente de que la norma posterior consagre un beneficio para el contribuyente (Sentencia de 26 de noviembre de 2009, expediente 16928).

Sentencia de 4 de febrero de 2010, expediente 17146. En esta sentencia, el Consejo de Estado dice que frente al inciso 3 del artículo 338 de la Constitución, la Corte Constitucional manifestó que la prohibición de cobrar tributos en el mismo período fiscal en que entra a regir la norma, es una medida de protección adoptada por el constituyente a favor de los administrados. Según el principio de irretroactividad, la ley rige hacia el futuro y las previsiones contenidas en normas sustanciales se aplican a los hechos o situaciones de hecho ocurridas bajo su vigencia. Concluye el Consejo de Estado que al tratarse de una norma tributaria que modifica aspectos sustanciales relacionados con el impuesto de renta, tributo que es de período, se aplica para el período que comience después de iniciar la vigencia (Sentencia de 4 de febrero de 2010, expediente 17146).

Sentencia de 17 de junio de 2010, Radicado 16427. El Consejo de Estado dice que, como lo ha señalado en ocasiones anteriores, no es posible la aplicación inmediata, ni la aplicación retroactiva de normas que afecten alguno de los elementos que estructuran los impuestos de período, pues ello implicaría la vulneración de las normas constitucionales ya mencionadas, disposiciones que precisamente procuran que los hechos ya formalizados jurídicamente y los que se encuentren en curso al momento de expedición de una ley, no se vean afectados por los cambios, en aras de la seguridad jurídica y de que haya certeza de las regulaciones de la obligación tributaria previamente a la causación del impuesto (principio de legalidad). Para el caso de los tributos de período, las normas deben regir con anterioridad a la iniciación del mismo. Agrega que los artículos 338 y 363 de la Carta Política proscriben de manera categórica la retroactividad de las leyes, sin diferenciar si son o no favorables al contribuyente, la ley aplicable es la vigente al inicio del período. Concluye que no tiene sustento alguno en el derecho tributario que se aplique el principio de favorabilidad propio de la legislación penal, pues los impuestos no constituyen un castigo, ni un agravio al contribuyente, sino que surgen de un deber de solidaridad de los ciudadanos, para coadyuvar con las cargas públicas. No puede considerarse desfavorable una norma fiscal que, por principio, pretende el bien común (Sentencia de 17 de junio de 2010, Radicado 16427).

Sentencia de 11 de noviembre de 2010, expediente 16337. En esta sentencia, el Consejo de 
Estado dice que la base del impuesto de renta es el resultado de hechos económicos ocurridos durante el año calendario que va desde el 1 de enero al 31 de diciembre y que no es posible la aplicación inmediata, ni la aplicación retroactiva de normas que afecten alguno de los elementos que estructuran tributos de período, pues ello implicaría la vulneración de las normas constitucionales ya mencionadas, disposiciones que precisamente procuran que los hechos ya formalizados jurídicamente y los que se encuentran en curso al momento de expedición de una ley, no se vean afectados por los cambios, en aras de la seguridad jurídica y de que haya certeza de las regulaciones de la obligación tributaria, previamente a la causación del impuesto (principio de legalidad). Para el caso de los tributos de período, las normas deben regir con anterioridad a su iniciación (Sentencia de 11 de noviembre de 2010, expediente 16337).

\section{Sentencia de 3 de marzo de 2011, Radica-} do 17443. En esta sentencia, el Consejo de Estado dice que, aunque podría pensarse que en virtud del principio de irretroactividad de la ley tributaria consagrado en el artículo 363 de la Constitución Política, la reducción solo cobija a los contratos otorgados o aceptados con posterioridad a la entrada en vigencia de la Ley 1111 de 2006, lo cierto es que las reducciones de tarifas son una especie de beneficio fiscal que favorece a los sujetos pasivos del impuesto. Según lo precisó la Corte Constitucional en la Sentencia C-006 de 1998 refiriéndose a impuestos de período y cuya doctrina es, a su vez, norma para interpretar las leyes, si una norma beneficia al contribuyente, al evitar que se aumenten sus cargas, en forma general, por razones de justicia y equidad puede aplicarse en el mismo período sin quebrantar el artículo 338 de la Constitución, porque la prohibición que esta norma contiene se dirige a impedir el aumento de las cargas al contribuyente, con regulaciones para períodos vencidos o en curso.

En otros términos, las normas con esas características pueden tener efectos retroactivos, y aplicarse a partir de su promulgación, a menos que el legislador expresamente lo haya prohibido, sin que por ello quebrante el artículo 338 de la Constitución, toda vez que las derogaciones tributarias que benefician al contribuyente se cobijan por la inmediatez (Sentencia de 3 de marzo de 2011, Radicado 17443).

Como se puede observar en esta sentencia, el Consejo de Estado acepta la aplicación del principio de favorabilidad de las normas sustantivas en materia tributaria.

\section{Sentencia de 6 de marzo de 2014, expe-} diente 19649. El Consejo de Estado en esta sentencia cita las sentencias de 15 de octubre de 1993, Expediente 4710, consejera ponente Consuelo Sarria-Olcos, y del 4 de febrero de 2010, Expediente 17146, consejera ponente Martha Teresa Briceño de Valencia para indicar que las normas que modifiquen alguno de los elementos estructurales del tributo, de un impuesto de período, solo podrán aplicarse para el que comience después de su entrada en vigencia. También cita la sentencia del 10 de julio de 1998, Expediente 8730, consejero ponente Delio Gómez-Leyva, para indicar que el constituyente, con el artículo 338, quiso prohibir la aplicación retroactiva de la norma tributaria, entendida esta no solo como las leyes, ordenan- 
zas y acuerdos, sino cualquier otra norma que regule contribuciones cuya base sea el resultado de hechos ocurridos durante un período determinado. De otra parte, se ha precisado que las disposiciones que establecen los elementos esenciales de los tributos - es decir, sujetos activo y pasivo, hechos generadores, bases gravables y tarifa-, tienen el carácter de "ley sustantiva"; por tanto, deben ser preexistentes al nacimiento de la obligación tributaria y su aplicación en manera alguna puede ser retroactiva, en virtud de los principios de legalidad e irretroactividad que forman parte del ordenamiento positivo (Sentencia de 6 de marzo de 2014, expediente 19649).

En la siguiente tabla se presenta la línea jurisprudencial del Consejo de Estado.

¿Es dable la aplicación del principio de favorabilidad de las normas sustantivas en el derecho tributario?

\begin{tabular}{cl}
\hline \multicolumn{1}{c|}{ Sí } & \multicolumn{1}{c}{ No } \\
\hline Sentencia de 17 de abril de 1998, Radicado 8331 & Sentencia de 15 de octubre de 1993, Expediente 4710 \\
& Sentencia de 7 de febrero de 1997, Expediente 8036 \\
& Sentencia de 5 de marzo de 1999, Radicado 9196 \\
& Sentencia de 19 de julio de 2000, Radicado 9907 \\
& Sentencia de 7 de diciembre de 2000, Radicado 10445 \\
& Sentencia de 3 de agosto de 2006, expediente 14897 \\
& Sentencia de 26 de octubre de 2006, Radicado 15177 \\
& Sentencia de 13 de septiembre de 2007, expediente 15503 \\
& Sentencia de 21 de noviembre de 2007, expediente 15584 \\
& Sentencia de 31 de julio de 2009, expediente 16016 \\
& Sentencia de 26 de octubre de 2009, expediente 16665 \\
& Sentencia de 26 de noviembre de 2009, expediente 16928 \\
& Sentencia de 4 de febrero de 2010, expediente 17146 \\
& Sentencia de 17 de junio de 2010, Radicado 16427 \\
& Sentencia de 11 de noviembre de 2010, expediente 16337
\end{tabular}

Sentencia de 3 de marzo de 2011, Radicado 17443

Sentencia de 6 de marzo de 2014, expediente 19649

Tabla 2. Línea jurisprudencial del Consejo de Estado

Fuente: elaboración propia

Como se puede apreciar, la línea jurisprudencial del Consejo de Estado es opuesta a la línea jurisprudencial sostenida por la Corte Constitucional en cuanto a la aplicación del principio de favorabilidad de las normas sustantivas en materia tributaria, aunque se encontraron dos sentencias en las cuales esta corporación acepta la aplicación del principio; estas constituyen referentes aislados, sin llegar a considerarse lo suficientemente fuertes como para cambiar la línea de pensamiento dominante en el período observado de 1993 
a 2014. Como se observa en la anterior tabla, predomina la posición de no aceptar la aplicación de las normas sustantivas favorables al contribuyente en el mismo período en que entraron en vigencia.

El Consejo de Estado hace una interpretación extensiva de la regla contenida en el inciso 3 del artículo 338 de la Constitución, pues interpreta que la palabra "período" contenida en esta norma se refiere al período fiscal, es decir, al período gravable, y no importa si se trata de meras expectativas de derecho o de derechos consolidados, pues siempre que se aplique la norma en el mismo período fiscal de su entrada en vigencia estaremos ante una aplicación retroactiva de la norma.

A continuación, se grafica la situación planteada:



Gráfico 2. Esquema de interpretación del principio de favorabilidad del Consejo de Estado Fuente: elaboración propia

\section{Resultados del análisis de la información}

Del análisis de las quince sentencias encontradas de la Corte Constitucional en el período de 1996 a 2012, que tratan acerca del principio de favorabilidad de las normas sustantivas en ma- teria tributaria, resaltan tres aspectos como los elementos fundamentales de la interpretación que hace la Corte Constitucional de normas sustantivas favorables al contribuyente que comienzan a aplicarse a partir de su vigencia en el mismo período gravable. 
Primero. La Corte Constitucional explica que la palabra "período" contenida en el inciso 3 del artículo 338 de la Constitución no tiene ningún adjetivo calificativo. Por lo tanto, este tribunal constitucional interpreta que la palabra "período" significa intervalo de tiempo y aclara que cuando la norma dice período siguiente, se refiere al período que se sigue a la entrada en vigencia de la norma, por lo que el período anterior, sería el período anterior al momento de entrada en vigencia de la norma. Así, dentro de un período gravable quedan incluidos dos subperíodos.

Segundo. La Corte Constitucional entiende que los conceptos de derechos adquiridos y de meras expectativas de derecho aplican en el derecho público, pero los derechos adquiridos se entienden como situaciones jurídicas consolidadas, los cuales en el derecho tributario se entienden como derechos consolidados y se presentan en el momento que estos derechos entran en el patrimonio de las personas o del Estado. La Corte Constitucional interpreta que al tratarse de tributos de período, el período en el que se forma la base gravable constituye el período gravable, el cual va desde al inicio del período gravable hasta antes del último instante en que termina el período, y en este se presentan meras expectativas de derecho en materia tributaria, que solo al finalizar el último instante o momento del período gravable se consolidan los derechos al entrar al patrimonio de las personas o del Estado, y precisamente en ese instante, al terminar al período gravable, se puede hablar de situaciones jurídicas consolidadas.

Tercero. La Corte Constitucional interpreta que si dentro del período gravable se expide una norma y esta entra en vigencia en el mismo período gravable, y afecta elementos estructurales del tributo, se deben tener en cuenta los efectos que estas normas producen en las cargas tributarias del contribuyente, entendiendo que son normas favorables cuando eliminan o disminuyen las cargas tributarias, y desfavorables cuando crean o aumentan las cargas tributarias. La Corte concluye que al tratarse de normas favorables al contribuyente en los anteriores términos, se pueden aplicar a partir del día siguiente al de su entrada en vigencia, porque no es una aplicación retroactiva de la norma, sino retrospectiva, toda vez que la Corte identifica que el período gravable no se ha consolidado, por lo que esos derechos no han entrado al patrimonio de las personas o del Estado, y por lo tanto se aplica a meras expectativas de derecho y no a situaciones jurídicas consolidadas.

Ahora, los tres aspectos anteriores de acuerdo con la posición asumida por el Consejo de Estado son totalmente opuestos a los de la Corte Constitucional, así tenemos que de una muestra de dieciocho sentencias encontradas en el período que va de octubre de 1993 hasta marzo de 2014, se encontró que en solo dos sentencias, el Consejo de Estado interpretó, aceptando la aplicación del principio de favorabilidad de las normas sustantivas, en estos dos casos el Consejo de Estado ha citado argumentos de las Sentencias C-185-97 y C-006-98 de la Corte Constitucional, para indicar que las normas favorables al contribuyente sí aplican en el mismo período gravable en que entraron en vigencia sin afectar el inciso 3 del artículo 338 de la Constitución. 
Pero estas dos sentencias son dos casos aislados de los dieciocho encontrados, pues se puede observar en la línea jurisprudencial desarrollada por el Consejo de Estado, que esta corporación ha mostrado de forma consistente su posición de no aceptar la posibilidad constitucional de aplicar las normas sustantivas favorables a los contribuyentes en el mismo período gravable en que estas han entrado en vigencia.

Los tres aspectos que se resaltan como los elementos fundamentales de la interpretación que hace el Consejo de Estado al tratarse de normas sustantivas favorables al contribuyente que comienzan a aplicarse a partir de su vigencia en el mismo período gravable son los siguientes:

Primero. El Consejo de Estado indica que la palabra "período" contenida en el inciso 3 del artículo 338 de la Constitución se refiere al período fiscal, es decir, califica la palabra "período" con el adjetivo fiscal, y aclara que cuando el texto de la norma dice "período siguiente", se refiere al período fiscal o período gravable que se sigue a la vigencia de la norma.

Segundo. El Consejo de Estado interpreta que al tratarse de tributos de período, el período en el que se forma la base gravable, constituye el período gravable, y va desde el inicio hasta el último instante en que termina el período gravable, aunque se está ante meras expectativas de derecho, la norma que entra en vigencia en ese mismo período gravable no puede afectarlas, pues se estaría violando el artículo 338 inciso 3 que establece que estas normas se deben aplicar en el período siguiente al de su entrada en vigencia.

Tercero. El Consejo de Estado interpreta que si dentro del período gravable se expide una norma, la cual entra en vigencia en el mismo período gravable, afectando los elementos estructurales del tributo, no interesa los efectos que estas normas producen en las cargas tributarias del contribuyente, ya sean favorables o desfavorables. El Consejo de Estado concluye que al tratarse de normas que entran en vigencia dentro del mismo período gravable su aplicación se hace en el siguiente período gravable.

\section{Conclusiones}

La Corte Constitucional ha mantenido una línea jurisprudencial según la cual la aplicación del principio de irretroactividad establecido en el artículo 363 inciso 2 de la Constitución no es absoluta cuando se trata de normas que benefician al contribuyente, ya que en estos casos pueden ser aplicadas en el mismo período gravable de su entrada en vigencia.

En palabras de la profesora Carolina AcostaRamos se presentan dos eventos: el primero es la adopción de cambios legislativos que se manifiestan al modificarse las leyes preexistentes, y el segundo consiste en la introducción de una nueva legislación. En estos dos eventos, el problema se presenta al definir cuál es el momento de aplicación de las normas, ya que estas normas tienen consecuencias en el patrimonio de las personas, por lo tanto se afecta el derecho de propiedad asociado con este patrimonio (Acosta-Ramos, 2004, p. 55).

De acuerdo con la jurisprudencia de la Corte Constitucional, en caso de que una norma que afecte los elementos estructurales de un tributo resulte favorable al contribuyente, su aplicación se haría de las siguientes formas, 
dependiendo de si la norma es derogatoria o es una norma nueva. Para comprender cuáles son las normas derogatorias, acudimos a la definición que al respecto hace el profesor Diego Martínez-Marulanda, quien expresa que se debe precisar qué se entiende por norma derogatoria, ya que la expresión "derogación” se emplea en un sentido amplio, como una expresión que comprende las demás formas en que la ley sale del ordenamiento jurídico dejando de regir, es decir, la ley deja de existir, por lo tanto la derogatoria es un género al que pertenecen las especies: modificación, derogación, abrogación y subrogación, que se describen a continuación: modificación: es la afectación parcial tácita de la vigencia de la ley, se reforma o se deja sin efecto una parte de la ley; derogación: es la afectación parcial expresa de la vigencia, se deja sin efectos parcialmente una ley; abrogación: es la afectación total expresa de la vigencia, se deja sin efectos toda la ley; y subrogación: es la afectación total tácita de la vigencia, es la derogatoria tácita (2000, p. 156).

Los casos que se pueden presentar, en armonía con la interpretación que hace la Corte Constitucional, acerca de la aplicación del principio de favorabilidad de las normas sustantivas en materia tributaria, son los siguientes:

Primero. Si se trata de una norma derogatoria, y el legislador no dispuso ninguna regla especial para su aplicación, la norma debe aplicarse prospectivamente, es decir, hacia el futuro, desde el día siguiente al de su entrada en vigencia.

Segundo. Si se trata de una norma derogatoria, y el legislador dispuso su aplicación en el mismo período fiscal al de su entrada en vigen- cia, la norma debe aplicarse prospectivamente, es decir, hacia el futuro, desde el día siguiente al de su entrada en vigencia.

En estos dos casos no estamos ante una aplicación retroactiva de la norma, sino retrospectiva, porque aplicarla dentro del mismo período gravable es aplicarla a meras expectativas y no a situaciones jurídicas consolidadas; por lo tanto, la Corte Constitucional concluye que aplicar la norma sustantiva favorable al contribuyente no es inconstitucional.

Además, en estos dos casos, aplicando la interpretación de período de la Corte Constitucional, se presenta el reparto o división del ejercicio fiscal o período gravable, es decir, hay dos subperíodos incluidos dentro del período gravable, uno que va desde el primer momento al inicio del período gravable hasta el día de entrada en vigencia de la norma, y otro que va desde el día siguiente al de entrada en vigencia la norma y el último momento del período gravable.

Tercero. Si se trata de una norma derogatoria, y el legislador de manera expresa en la norma establece su aplicación a partir del 1 de enero del año siguiente, o incluso de una fecha posterior, no hay ninguna violación a la Constitución, dado que el legislador cuenta con amplio margen de configuración legislativa y puede disponer que una norma aplique en una fecha futura $y$ esto no viola el texto constitucional.

Cuarto. Si se trata de una norma nueva, y el legislador no dispuso ninguna regla especial para su aplicación, la norma debe aplicarse prospectiva y retrospectivamente, es decir, prospectiva o hacia el futuro, desde el día siguiente al de su entrada en vigencia, y retrospectiva en el mismo período fiscal al de su 
entrada en vigencia. Por lo tanto, la norma se aplica a todo el período fiscal o período gravable. Ahora, aplicarla dentro del mismo período gravable es aplicarla a meras expectativas y no a situaciones jurídicas consolidadas, por lo tanto la norma no es inconstitucional.

Quinto. Si se trata de una norma nueva, y el legislador dispuso su aplicación en el mismo período fiscal de su entrada en vigencia, se aplica a todo el período, y no estamos ante una aplicación retroactiva de la norma sino retrospectiva, porque aplicarla dentro del mismo período gravable es aplicarla a meras expectativas y no a situaciones jurídicas consolidadas, por lo tanto la norma no es inconstitucional.

Sexto. Si se trata de una norma nueva, y el legislador de manera expresa en la norma establece su aplicación a partir del primero de enero del año siguiente, o incluso de una fecha posterior, no hay ninguna violación a la Constitución, dado que el legislador cuenta con amplio margen de configuración legislativa y puede disponer que una norma aplique en una fecha futura y esto no viola el texto constitucional.

Ahora, aplicar la norma sustantiva favorable en el mismo período fiscal de su entrada en vigencia no atenta contra el principio de la confianza legítima que, de acuerdo con la Corte Constitucional, se deriva del artículo 83 de la Constitución que regula la buena fe (Sentencia C-1215-01); agrega este tribunal que el principio de la confianza legítima es un corolario de aquel de la buena fe, el cual consiste en que el Estado no puede súbitamente alterar las reglas de juego que regulaban sus relaciones con los particulares, sin que se les otorgue a estos un período de transición para que ajus- ten su comportamiento a una nueva situación jurídica (Sentencia C-131-04), dice el máximo tribunal de lo Constitucional, que la confianza legítima consiste en que el ciudadano debe poder evolucionar en un medio jurídico estable y previsible, en el cual pueda confiar (Sentencia C-131-04).

En este orden de ideas, las normas sustantivas favorables al contribuyente no alterarán súbitamente las reglas de juego que regulan las relaciones tributarias entre el Estado y los particulares, pues la confianza legítima no se ve afectada porque son normas que disminuyen las cargas tributarias al contribuyente, pero al tratarse de normas sustantivas desfavorables al contribuyente que alterarán súbitamente las reglas de juego que regulan sus relaciones del Estado con los contribuyentes al aumentar sus cargas fiscales, estas se deben aplicar en el período fiscal siguiente al de su entrada en vigencia, pues así se le otorga al contribuyente un período de transición para que ajuste su comportamiento a una nueva situación jurídica.

Ahora pasamos a las conclusiones correspondientes con la posición asumida por Consejo de Estado en relación con la aplicación de principio de favorabilidad de las normas sustantivas en materia tributaria, que es totalmente opuesta a la jurisprudencia de la Corte Constitucional.

El Consejo de Estado califica la palabra "período" contenida en el artículo 338 de la Constitución con el adjetivo fiscal; por lo tanto, concluye el Consejo de Estado en este caso, que período es período fiscal, y bajo esta interpretación ninguna norma que haya entrado en vigencia en el mismo período fiscal puede aplicarse en el mismo período fiscal, porque de 
aplicarse sería una aplicación retroactiva de la norma y nunca retrospectiva.

Como se aprecia en el presente escrito, hay una contradicción entre la posición asumida por la Corte Constitucional y la posición del Consejo de Estado. Esta contradicción entre altas cortes, conforme el lenguaje popular, se conoce como "el choque de trenes", con infortunadas consecuencias como la incertidumbre y la inseguridad jurídica que se generan ante este tipo de situaciones en el sistema jurídico, pues es una forma de hacer nugatorios los derechos de los contribuyentes establecidos en la jurisprudencia de la Corte Constitucional por parte del Consejo de Estado.

Desde el punto de vista práctico, asumir la posición de la Corte Constitucional puede derivar en un proceso de índole administrativa, que finalmente es dirimido ante la jurisdicción contenciosa administrativa, cuya máxima autoridad es el Consejo de Estado; en esa medida, la aplicación del concepto de favorabilidad tiene altos riesgos de no ser procedente.

Lo anterior tiende a ser desalentador; sin embargo, es factible dilucidar la posibilidad de la aplicación del principio de favorabilidad de las normas sustantivas, pues aun siendo el Consejo de Estado el tribunal de cierre de los procesos contenciosos administrativos, quedaría burlada la jurisprudencia de la Corte Constitucional, si no hubiera nada qué hacer. El máximo tribunal Constitucional, como guardián de la Constitución fija el sentido para que las leyes se ajusten a la Constitución. Además, en el uso de sus facultades ha fijado el alcance de los argumentos de sus sentencias en la Sentencia C-131-93, en la cual indica que la ratio decidendi de sus sen- tencias obliga a los jueces. En este orden de ideas, ha indicado esta Corporación el sentido de la palabra "período" en el contexto del inciso 3 del artículo 338, y la decisión de aplicar el principio de favorabilidad de las normas sustantivas en materia tributaria.

Por lo tanto, sí hay instancias jurídicas a las cuales recurrir, pues si el Consejo de Estado desconoce la línea jurisprudencial de la Corte Constitucional acerca de la aplicación del principio de favorabilidad de las normas sustantivas en materia tributaria, estando obligado a hacerlo, puede demandarse en acción de tutela por violación al derecho fundamental del debido proceso; y aún más, si no prospera la acción de tutela, procede demandar ante los tribunales internacionales por la violación al derecho fundamental del debido proceso. Pero todo esto es una estrategia utilizada por el Consejo de Estado para hacer nugatorios los derechos, en este caso, los derechos de los contribuyentes ante la línea de interpretación asumida por la Corte Constitucional, pues es un despropósito que se tenga que recurrir a un proceso que puede llevar más de dos o tres décadas, e incluso llegar a una fila interminable de quién sabe cuántas décadas para que los tribunales internacionales se pronuncien, si es que llegan a pronunciarse al respecto.

Por último, hay que decir que se observa poco rigor científico e investigativo en el Consejo de Estado, pues no se ha respaldado en el derecho comparado, ni en las deliberaciones de la Asamblea Nacional Constituyente con respecto al inciso 3 del artículo 338 de la Constitución, como sí lo ha hecho la Corte Constitucional, teniendo en cuenta que, aunque 
el derecho comparado no es fuente formal del derecho, sí es una fuente auxiliar. Así, el sentido fijado en la ratio decidendi en las sentencias de la Corte Constitucional que establecen el principio de favorabilidad de las normas tributarias sustantivas, debería ser respetado en el ordenamiento jurídico colombiano por todos los jueces, incluidos los magistrados del Consejo de Estado. Al no respetarse la jurisprudencia de la Corte Constitucional por parte del Consejo de Estado, siendo este tribunal el tribunal de cierre contencioso administrativo, la consecuencia es que se impacta el sistema jurídico colombiano de forma negativa al generarse desconfianza e inseguridad jurídica, al punto de hacerse nugatorio un derecho establecido en la jurisprudencia constitucional.

Para resolver el conflicto que se genera por el "choque de trenes" entre estas dos corporaciones, se propone que una institución de los órganos que conforman el Estado funja como un tercero independiente y exprese un concepto al respecto, con el fin de que la jurisprudencia con relación al principio de favorabilidad de las normas sustantivas en materia tributaria sea unificada en un único concepto que sea respetado por las Altas Cortes colombianas. Ese órgano que puede conceptuar al respecto, debe ser la Procuraduría General de la Nación, apelando a sus funciones constitucionales establecidas en el artículo 277 de la Constitución, cuando dice que entre sus funciones tiene la vigilancia del cumplimiento de la Constitución, las leyes, las decisiones judiciales y los actos administrativos; la protección de los derechos humanos y el aseguramiento de su efectividad, con el auxilio del Defensor del Pueblo; defender los intereses de la sociedad; defender los intereses colectivos, en especial el ambiente. Intervenir en los procesos y ante las autoridades judiciales o administrativas, cuando sea necesario en defensa del orden jurídico, del patrimonio público, o de los derechos y garantías fundamentales.

\section{Referencias}

Acosta-Ramos, Carolina (2004). ¿Es absoluto el principio de irretroactividad de la ley tributaria? Revista Derecho Fiscal, 2, 55-63. Disponible en: http://papers.ssrn.com/sol3/ papers.cfm?abstract_id=1521652

Ariza-Zapata, Carolina (2012). La ductilidad de los principios constitucionales en materia tributaria. Revista Estudios de Derecho de la Universidad de Antioquia, 69 (153), 287314. Disponible en: https://aprendeenlinea. udea.edu.co/revistas/index.php/red/article/ download/14151/12510

Colombia (1991). Constitución Política. Disponible en: http://www.secretariasenado. gov.co/senado/basedoc/constitucion_politica_1991.html

Colombia (1975). Decreto 187 de 1975, por medio del cual se dictan disposiciones reglamentarias en materia de impuesto sobre la renta y complementarios. Diario Oficial, 34.259, 18 de febrero de 1975. Disponible en: http://normograma.sena.edu.co/docs/ decreto_0187_1975.htm

Colombia (1989). Decreto 624 de 1989, por el cual se expide el Estatuto Tributario de los Impuestos Administrados por la Dirección General de Impuestos Nacionales. Diario Oficial, 38.756, 30 de marzo de 1989. Dispo- 
PRINCIPIO DE FAVORABILIDAD DE LAS NORMAS SUSTANTIVAS EN MATERIA TRIBUTARIA / C. RESTREPO / 453

nible en: http://www.secretariasenado.gov. co/senado/basedoc/estatuto_tributario.html

Colombia (1992). Ley 6 de 1992, por la cual se expiden normas en materia tributaria, se otorgan facultades para emitir títulos de deuda pública interna, se dispone un ajuste de pensiones del sector público nacional y se dictan otras disposiciones. Diario Oficial, 40.490, 30 de junio de 1992. Disponible en: http://www.secretariasenado.gov.co/senado/ basedoc/ley_0006_1992.html

Colombia (1995). Ley 223 de 1995, por la cual se expiden normas sobre racionalización tributaria y se dictan otras disposiciones. Diario Oficial, 42.160, 22 de diciembre de 1995. Disponible en: http://www. secretariasenado.gov.co/senado/basedoc/ ley_0223_1995.html

Colombia (2000). Ley 601 de 2000, por la cual se concede una autorización a los contribuyentes del Impuesto Predial Unificado en el Distrito. Diario Oficial, 44.100, 26 de julio de 2000. Disponible en: http://www. secretariasenado.gov.co/senado/basedoc/ ley_0601_2000.html

Colombia (2003). Ley 863 de 2003, por la cual se establecen normas tributarias, aduaneras, fiscales y de control para estimular el crecimiento económico y el saneamiento de las finanzas públicas. Diario Oficial, 45.415, de 29 de diciembre de 2003. Disponible en: http://www.secretariasenado.gov.co/senado/ basedoc/ley_0863_2003.html

Colombia (2006). Ley 1111 de 2006, por la cual se modifica el estatuto tributario de los impuestos administrados por la Dirección de Impuestos y Aduanas Nacionales. Diario
Oficial, 46.494, de 27 de diciembre de 2006. Disponible en: http://www.secretariasenado.gov.co/senado/basedoc/ley_1111_2006. html

Consejo de Estado. Sala de lo Contencioso Administrativo. Sección Cuarta. Radicado 4710, 15 de octubre de 1993. Consejera ponente Consuelo Sarria-Olcos. Disponible en: http://190.24.134.114:8080/WebRelatoria/ce/index.xhtml

Consejo de Estado. Sala de lo Contencioso Administrativo. Sección Cuarta. Expediente 8036, 7 de febrero de 1997. Consejero ponente Delio Gómez-Leyva. Disponible en: http://190.24.134.114:8080/WebRelatoria/ ce/index.xhtml

Consejo de Estado. Sala de lo Contencioso Administrativo. Sección Cuarta. Radicado 8331, 17 de abril de 1998. Consejero ponente Germán Ayala-Mantilla. Disponible en: http://190.24.134.114:8080/WebRelatoria/ ce/index.xhtml

Consejo de Estado. Sala de lo Contencioso Administrativo. Sección Cuarta. Radicado 9196, 5 de marzo de 1999. Consejero ponente Delio Gómez-Leyva. Disponible en: http://190.24.134.114:8080/WebRelatoria/ ce/index.xhtml

Consejo de Estado. Sala de lo Contencioso Administrativo. Sección Cuarta. Radicado 9907, 19 de junio de 2000. Consejero ponente Germán Ayala-Mantilla. Disponible en: http://190.24.134.114:8080/WebRelatoria/ce/index.xhtml

Consejo de Estado. Sala de lo Contencioso Administrativo. Sección Cuarta. Radicado 10445, 7 de diciembre de 2000. Consejero 
ponente Daniel Manrique-Guzmán. Disponible en: http://190.24.134.114:8080/WebRelatoria/ce/index.xhtml

Consejo de Estado. Sala de lo Contencioso Administrativo. Sección Cuarta. Expediente 14897, 3 de agosto de 2006. Consejera ponente María Inés Ortiz-Barbosa. Disponible en: http://190.24.134.114:8080/WebRelatoria/ce/index.xhtml

Consejo de Estado. Sala de lo Contencioso Administrativo. Sección Cuarta. Radicado 15177, 26 de octubre de 2006. Consejera ponente María Inés Ortiz-Barbosa. Disponible en: http://190.24.134.114:8080/WebRelatoria/ce/index.xhtml

Consejo de Estado. Sala de lo Contencioso Administrativo. Sección Cuarta. Expediente 15503, 3 de septiembre de 2007. Consejera ponente Ligia López-Díaz. Disponible en: http://190.24.134.114:8080/WebRelatoria/ ce/index.xhtml

Consejo de Estado. Sala de lo Contencioso Administrativo. Sección Cuarta. Expediente 15584, 21 de noviembre de 2007. Consejera ponente Ligia López-Díaz. Disponible en: http://190.24.134.114:8080/WebRelatoria/ ce/index.xhtml

Consejo de Estado. Sala de lo Contencioso Administrativo. Sección Cuarta. Expediente 16016, 31 de julio de 2009. Consejero ponente Héctor J. Romero-Díaz. Disponible en: http://190.24.134.114:8080/WebRelatoria/ce/index.xhtml

Consejo de Estado. Sala de lo Contencioso Administrativo. Sección Cuarta. Expediente 16665, 26 de octubre de 2009. Consejera ponente Martha Tere- sa Briceño de Valencia. Disponible en: http://190.24.134.114:8080/WebRelatoria/ ce/index.xhtml

Consejo de Estado. Sala de lo Contencioso Administrativo. Sección Cuarta. Expediente 16928, 26 de noviembre de 2009. Consejera ponente Martha Teresa Briceño de Valencia. Disponible en: http://190.24.134.114:8080/WebRelatoria/ ce/index.xhtml

Consejo de Estado. Sala de lo Contencioso Administrativo. Sección Cuarta. Expediente 17146, 4 de febrero de 2010. Consejera ponente Martha Teresa Briceño de Valencia. Disponible en: http://190.24.134.114:8080/ WebRelatoria/ce/index.xhtml

Consejo de Estado. Sala de lo Contencioso Administrativo. Sección Cuarta. Expediente 16337, 11 de marzo de 2010. Consejero ponente Hugo Fernando Bastidas-Bárcenas. Disponible en: http://190.24.134.114:8080/ WebRelatoria/ce/index.xhtml

Consejo de Estado. Sala de lo Contencioso Administrativo. Sección Cuarta. Radicado 16427, 10 de junio de 2010. Consejero ponente William Giraldo-Giraldo. Disponible en: http://190.24.134.114:8080/WebRelatoria/ce/index.xhtml

Consejo de Estado. Sala de lo Contencioso Administrativo. Sección Cuarta. Radicado 17443, 3 de marzo de 2011. Consejera ponente Carmen Teresa Ortiz de Rodríguez. Disponible en: http://190.24.134.114:8080/ WebRelatoria/ce/index.xhtml

Consejo de Estado. Sala de lo Contencioso Administrativo. Sección Cuarta. Radicado 19649, 6 de marzo de 2014. Consejera po- 
PRINCIPIO DE FAVORABILIDAD DE LAS NORMAS SUSTANTIVAS EN MATERIA TRIBUTARIA / C. RESTREPO / 455

nente Martha Teresa Briceño de Valencia. Disponible en: http://190.24.134.114:8080/ WebRelatoria/ce/index.xhtml

Corredor-Alejo, J. Orlando (2011). Aplicación de normas tributarias favorables: visión panorámica desde la Corte, el Consejo de Estado y la DIAN. Revista Instituto Colombiano de Derecho Tributario, 65, 49-80. Disponible en: http://www.webicdt.net:8080/ sitios/principal/centrodeinvestigacion/Lists/ Artculos\%20Revistas/Attachments/24/ JESUS\%20CORREDOR.pdf

Corte Constitucional. Sentencia C-131-93, 1 de abril de 1993. Magistrado ponente Alejandro Martínez-Caballero. Disponible en: http://www.corteconstitucional.gov.co/ relatoria/1993/c-131-93.htm

Corte Constitucional. Sentencia C-149-93, 22 de abril de 1993. Magistrado ponente José Gregorio Hernández-Galindo. Disponible en: http://www.corteconstitucional.gov.co/ relatoria/1993/c-149-93.htm

Corte Constitucional. Sentencia C-527-96, 10 de octubre de 1996. Magistrado ponente Jorge Arango-Mejía. Disponible en: http://www.corteconstitucional.gov.co/ relatoria/1996/c-527-96.htm

Corte Constitucional. Sentencia C-185-97, 10 de abril de 1997. Magistrado ponente José Gregorio Hernández-Galindo. Disponible e4n: http://www.corteconstitucional.gov.co/ relatoria/1997/c-185-97.htm

Corte Constitucional. Sentencia C-006-98, 22 de enero de 1998. Magistrado ponente Antonio Barrera-Carbonell. Disponible en: http:/www.corteconstitucional.gov.co/ relatoria/1998/c-006-98.htm
Corte Constitucional. Sentencia C-063-98, 5 de marzo de 1998. Magistrados ponentes Jorge Arango-Mejía \& José Gregorio Hernández-Galindo. Disponible en: http://www.corteconstitucional.gov.co/ relatoria/1998/c-063-98.htm

Corte Constitucional. Sentencia C-926-00, 19 de julio de 2000. Magistrado ponente Carlos Gaviria-Díaz. Disponible en: http://www.corteconstitucional.gov.co/ relatoria/2000/c-926-00.htm

Corte Constitucional. Sentencia C-619-01, 14 de junio de 2001. Magistrado ponente Marco Gerardo Monroy-Cabra. Disponible en: http://www.corteconstitucional.gov.co/ relatoria/2001/c-619-01.htm

Corte Constitucional. Sentencia C-806-01, 1 de agosto de 2001. Magistrada ponente Clara Inés Vargas-Hernández. Disponible en: http://corteconstitucional.gov.co/ relatoria/2001/C-806-01.htm

Corte Constitucional. Sentencia C-922-01, 29 de agosto de 2001. Magistrado ponente Marco Gerardo Monroy-Cabra. Disponible en: http://www.corteconstitucional.gov.co/ relatoria/2001/c-922-01.htm

Corte Constitucional. Sentencia C-1215-01, 21 de noviembre de 2001. Magistrado ponente Rodrigo Escobar-Gil. Disponible en: http://www.corteconstitucional.gov.co/ relatoria/2001/c-1215-01.htm

Corte Constitucional. Sentencia C-1251-01, 28 de noviembre de 2001. Magistrada ponente Clara Inés Vargas-Hernández. Disponible en: http://corteconstitucional.gov.co/ relatoria/2001/c-1251-01.htm 
Corte Constitucional. Sentencia C-131-04, 19 de febrero de 2004. Magistrado ponente Clara Inés Vargas-Hernández. Disponible en: http://www.corteconstitucional.gov.co/ relatoria/2004/c-131-04.htm

Corte Constitucional. Sentencia C-809-07, 3 de octubre de 2007. Magistrado ponente Manuel José Cepeda-Espinosa. Disponible en: http://www.corteconstitucional.gov.co/ relatoria/2007/c-809-07.htm

Corte Constitucional. Sentencia C-952-07, 14 de noviembre de 2007. Magistrado ponente Jaime Araújo-Rentería. Disponible en: http://www.corteconstitucional.gov.co/ relatoria/2007/c-952-07.htm

Corte Constitucional. Sentencia C-430-09, 1 de julio de 2009. Magistrado ponente Juan Carlos Henao-Pérez. Disponible en: http://www.corteconstitucional.gov.co/ relatoria/2009/c-430-09.htm

Corte Constitucional. Sentencia C-686-11, 19 de septiembre de 2011. Magistrado ponente Gabriel Eduardo Mendoza-Martelo. Disponible en: http://www.corteconstitucional. gov.co/relatoria/2011/c-686-11.htm

Corte Constitucional. Sentencia C-878-11, 22 de noviembre de 2011. Magistrado ponente Juan Carlos Henao-Pérez. Disponible en: http://www.corteconstitucional.gov.co/ relatoria/2011/c-878-11.htm
Corte Constitucional. Sentencia C-785-12, 10 de octubre de 2012. Magistrado ponente Jorge Iván Palacio-Palacio. Disponible en: http://www.corteconstitucional.gov.co/ relatoria/2012/c-785-12.htm

López-Medina, Diego Eduardo (2006). El derecho de los jueces: obligatoriedad del precedente constitucional, análisis de sentencias y líneas jurisprudenciales y teoría del derecho judicial. $2^{a}$ ed. Bogotá: Ediciones Uniandes y Legis Editores S.A.

Martínez-Marulanda, Diego (2000). Fundamentos para una introducción al derecho. Medellín: Editorial Universidad de Antioquia.

- Fecha de recepción: 16 de febrero de 2015

- Fecha de aceptación: 11 de mayo de 2015

- Disponible en línea: 01 de agosto de 2015

\section{Para citar este artículo}

Restrepo-Pineda, Carlos Mario (2015). Principio de favorabilidad de las normas sustantivas en materia tributaria. Choque de trenes entre la Corte Constitucional y el Consejo de Estado. Cuadernos de Contabilidad, 16 (41), 429-456. http://dx.doi. org/10.11144/Javeriana.cc16-41.pfns 